\title{
Water-Energy Prototype Model for the NEMS Modeling Platform: Thermoelectric Water Demand and Its Implications on Regional Electricity Market
}

\author{
Erik Shuster ${ }^{1}$, Arun K. S. Iyengar'1, Lessly Goudarzi², Dale Keairns' ${ }^{1}$, Christa Court ${ }^{3}$, \\ Charles Zelek ${ }^{1}$ \\ ${ }^{1}$ National Energy Technology Laboratory, Pittsburgh, USA \\ ${ }^{2}$ Onlocation Inc., Vienna, USA \\ ${ }^{3}$ University of Florida, Gainesville, USA \\ Email: erik.shuster@netl.doe.gov
}

How to cite this paper: Shuster, E., Iyengar, A.K.S., Goudarzi, L., Keairns, D., Court, C. and Zelek, C. (2017) Water-Energy Prototype Model for the NEMS Modeling Platform: Thermoelectric Water Demand and Its Implications on Regional Electricity Market. Journal of Water Resource and Protection, 9, 1449-1468. https://doi.org/10.4236/jwarp.2017.912093

Received: October 5, 2017

Accepted: November 26, 2017

Published: November 29, 2017

Copyright $\odot 2017$ by authors and Scientific Research Publishing Inc. This work is licensed under the Creative Commons Attribution International License (CC BY 4.0).

http://creativecommons.org/licenses/by/4.0/

\begin{abstract}
A simplified energy-water prototype model has been developed at the National Energy Technology Laboratory (NETL) as a part of a larger effort to comprehensively model energy-water interactions. The NETL Water-Energy Model (NWEM) prototype passively couples a variety of data on water supply, water availability, and power plant water use with the National Energy Modeling System (NEMS) power generation forecasts. NWEM operates at a watershed level and its efficacy in resolving local water supply and water-use trade-offs was demonstrated using data from Sandia National Laboratory along with a water supply scenario projected by the World Resources Institute (WRI). The prototype model only passively utilized a forecast of power generation from an existing forecast; the model's choices were limited to purchases or retrofitting to meet future water supply constraints. NETL is continuing to integrate the water sub-module into the NEMS framework, which will allow active interaction between the water market and power markets, extending the industry's ability to re-dispatch its generating units with the price of water as one of the variable costs.
\end{abstract}

\section{Keywords}

Energy-Water Nexus, Thermoelectric, Cooling Systems, Power Plant Retrofits

\section{Introduction}

The availability of water for electric power generation is a multidimensional 
problem that is dependent upon the source of the water, the fuel type, the power generation technology, the water constraint (scarcity or thermal limits), and the demand from competing sources. The United States (U.S.) Department of Energy's (DOE) National Energy Technology Laboratory (NETL) is exploring methods for examining the relative severity of the threats associated with water availability for electric power generation and for estimating the costs and benefits associated with mitigating their impacts.

As part of this effort, NETL aims to develop tools and metrics that allow for a better understanding of power plant water utilization under potential water constrained futures. The result of this effort is to inform the direction of NETL research and development (R\&D) to mitigate the impact of water availability threats on current and future fossil-fueled electric power generation capacity. Figure 1 displays a conceptual diagram for a comprehensive water-energy model that couples an energy market model with representations of various water demand sectors and water supply considerations, including the influences of changes in population, economic size and structure, climate scenarios, and policy on the water availability over time.

NETL has developed a simple prototype water-energy model that represents the first step toward integrating water supply, water use, and water availability data into the U.S. Energy Information Administration's (EIA) National Energy Modeling System (NEMS), as part of a multi-phased development of the more complete water-energy model envisioned in Figure 1. This report describes the prototype water-energy model referred to as the NETL Water-Energy Model (NWEM) and the results of initial analyses undertaken to investigate the types of changes in power plant water demand that might occur across a range of water availability scenarios. The following Background section provides additional

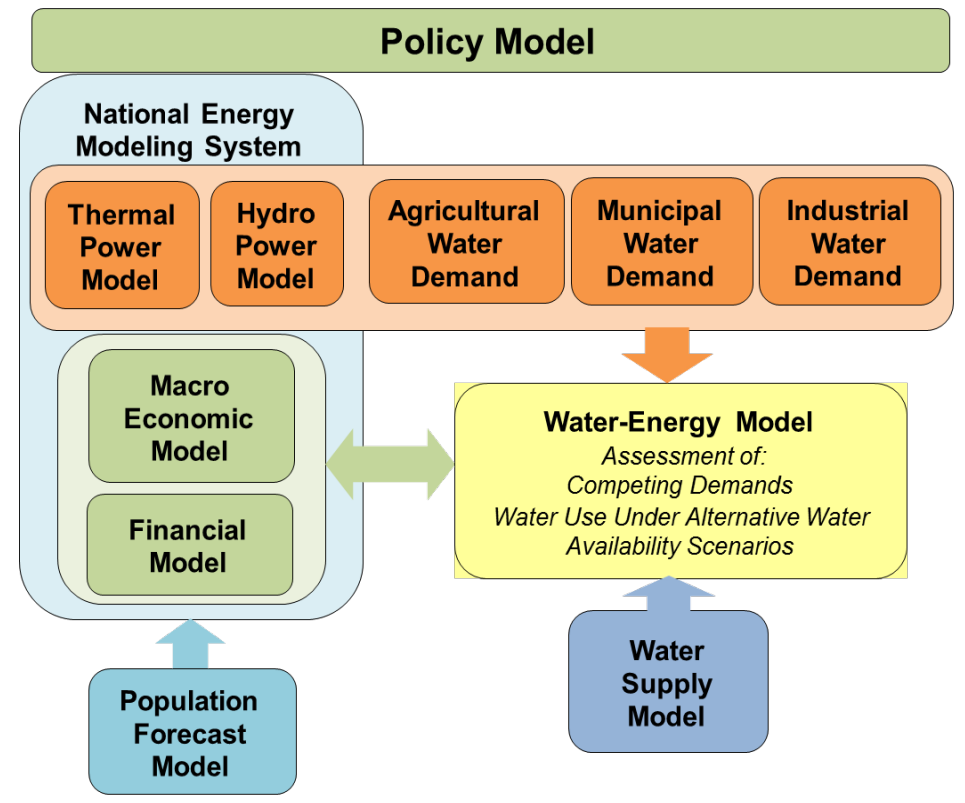

Figure 1. Conceptual schematic of a comprehensive water-energy model. 
background and a brief literature review. The Model Overview section provides a discussion of salient aspects of the model design, the main assumptions, and the reference water availability data. The Scenario section describes the specific water availability and cost data used for the initial analyses. The Results section summarizes the results on a national basis and subsequently showcases the NWEM's capabilities by focusing on a specific selected watershed experiencing a reduction in water available over time. Finally, the Discussion section reviews the limitations of the present analyses and discusses the next steps in the development of a fully NEMS-integrated version of the NWEM.

\section{Background}

Inconsistencies between the growing U.S. electric demand and the availability of water resources required to meet the demand were recognized in several initial studies [1] [2] [3]. NETL investigated the potential water vulnerabilities for existing coal-fired power plants ca. 2007 and concluded that 70 percent of the coal-fired power plants were vulnerable to potential supply and demand concerns [4]. The water-electricity trade-off was further highlighted by subsequent studies [5] [6] that projected future water demands using a contemporaneous forecast of the energy mix. Since these earlier investigations, there have been a variety of system-level studies that have analyzed the implications of long-term energy production on water consumption. These studies varied in the degree of complexity, geographic resolution, time horizons, and intent [7]. Projected global trends in water withdrawal and consumption characteristics of fourteen regions over the 21st century under different socioeconomic scenarios including population growth, electricity demand, and climate change have been investigated in an integrated fashion using the global change assessment model (GCAM) [8] [9] [10] [11]. The overall U.S. water consumption was found to increase while water withdrawal was generally observed to be stable in these studies, which modeled the whole of U.S. as one region. Liu et al. [12] employed GCAM-USA to examine trends in water usage across the states within the U.S.

Earlier analyses to characterize U.S. water usage and demand have relied on the energy forecasts from NEMS through direct simulations or [13] [5] [14] [15]. While integrated assessment models using the system dynamics approach have been applied on a global biosphere scale [16], other studies [17] [18] [19] have applied the system modeling language to examine the impact of local water constraints on the interaction between a local electricity system with its regional municipal water and waste water systems. Multi-agent learning-based predictive models have also been suggested to investigate market level effects under stochastic demand conditions as well as under water and carbon dioxide taxes [20] [21]. The studies of Yates et al. [22] [23] [24] include detailed modeling of local watersheds using the water evaluation and planning (WEAP) model along with thermoelectric water usage predicted by the regional energy deployment system (ReEDS). Stillwell [25] evaluated the regional water trade-offs in the state of 
Texas including a consideration of local water rights.

Recognizing the strong regional dependence of the energy-water nexus, there has been a systematic development of tools to investigate the interdependencies using the regionally resolved ReEDS. Several studies [26] [27] have investigated water-energy constraints under different geographic resolutions largely based on the methodology proposed by Macknick et al. [28]. These models have been extended to look at the issue of water rights recently [29]. The Water Resource System (WRS), an extensive model of the U.S. water resources, has also been coupled with ReEDS model energy forecasts under the Massachusetts Institute of Technology Integrated Global System Model Framework [30].

However, there have been no studies linking the NEMS platform to a water resource platform in a similar fashion. Accordingly, NETL has embarked on a program to include the impact of the cost and availability of local water resources into the decision framework of the widely used NEMS energy market modeling platform. The NWEM described in this paper passively couples a variety of data on water supply, water availability, and power plant water use with NEMS model outputs as a first step in the development of an actively coupled energy-water model.

\section{Model Overview}

\subsection{Model Scope}

The schematic for the simplified NWEM prototype is shown in Figure 2. The aspects of the water-energy model that have been implemented currently are also

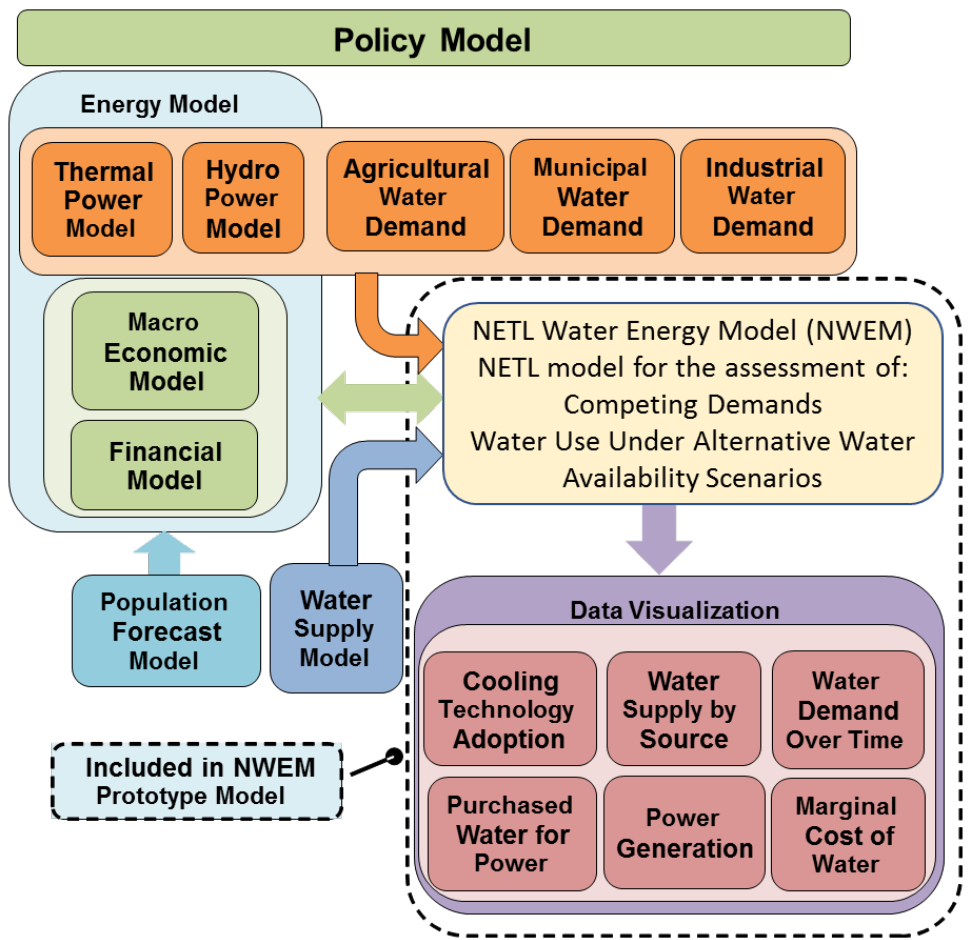

Figure 2. Schematic of simplified NWEM prototype. 
highlighted. The NWEM prototype is designed to utilize outputs associated with specific NEMS (currently, version 2016 or earlier) cases to produce a variety of key results that can be fed directly into a customized data visualization program to evaluate the model results. A sampling of the types of data that can be displayed are provided in the Results section of this paper. In the next phase, we intend to actively couple the NWEM with NEMS routines to include water use as an additional parameter in the optimization kernel.

\subsection{Model Design}

The NWEM is a multi-period linear programming (LP) model that minimizes the cost of satisfying the demand for water in each Hydrologic Unit CodeHUC8 ${ }^{1}$ region (across all demand sectors). The model incorporates the seasonal variation in water availability and demand. The model steps through time (currently from year 2015 to 2030) looking forward at the seasonal availability of water and the costs of satisfying demand for water in the current and future periods. Looking ahead across the planning horizon (currently set at 10 years), the NWEM performs an economic trade-off between purchasing water at various costs from constrained water sources or spending capital to retrofit power plants to use cooling technologies that require less water. The minimum net present value of the mix of purchasing water from alternative sources versus investing in retrofit cooling technologies that reduce the need for water is selected. The term "retrofit" is used in this paper to represent cooling technology retrofits for sake of brevity. The NWEM assumes that each watershed (HUC8) region is assumed a closed system of water supply and demand with no water sharing between watersheds.

The look ahead over the next 10 years allows for the proper cost comparison of the financing of long-term capital investments that reduce water usage over a long period to the costs of purchasing water over that same long-term horizon and allows for the reductions in water availability in the future to impact the retrofit decisions.

Retrofit decisions are made on an annual basis in MW of cooling capacity. This allows for any season in that planning period using it once it is built. Additionally, retrofits built in earlier planning periods are available to use in future planning periods. As such, the cost of a given retrofit is spread out across all periods and seasons that derive benefit from it in the form of reduced expenditures on water purchases. Additional details in the form of a simplified example of a power plant's decision process related to the marginal cost of water can be found in a separate working paper [31].

\subsection{Water Resources}

A team of researchers with the Water Security Program at Sandia National La-

${ }^{1}$ This is the smallest element of the hydrological units referred to as a cataloging unit or watershed. See Hydrologic Unit Maps: What are hydrologic units? For a more complete description. 
boratory (SNL) has developed a database related to water availability in 2012, its cost, and use for 38 U.S. states within the contiguous U.S. ${ }^{2,3}$ The database (hereafter, referred to as the Sandia data) contains information at the HUC8 or watershed level ${ }^{4}$. The data describes the amount of water that is currently used by four competing sectors (municipal and industrial (M\&I), agricultural, thermoelectric power generation, and environmental). Water use by the agricultural and the M\&I sectors are also projected for the year 2030. The availability of water (after satisfying the sectoral demands) for five unique sources (unappropriated surface water, unappropriated groundwater, appropriated surface and groundwater ${ }^{5}$, municipal wastewater, and brackish groundwater) is identified. The Sandia data also include an estimate of the associated costs to acquire, convey, and treat the water, as necessary, for each of the five sources.

The NWEM data structure is designed to support a variety of temporal variations in the water uses of the competing sectors. However, in the present analysis, the water use for M\&I, agricultural, and environmental users were linearly interpolated from 2012 to 2030 from the Sandia data set based on the 2030 projections. The historical surface water flow data from the United States Geological Service was used to set the seasonal median and percentiles of water availability for each watershed region ${ }^{6}$. Alternate formulations can be easily accommodated by the NWEM data structure.

The source of water for power plants was taken from the Union of Concerned Scientists (UCS) EW3 Energy-Water Database ${ }^{7}$ along with the Sandia data. Plants with missing water sources were assigned the same source type as the largest plant with the same fuel type within the watershed. Agriculture is assumed to derive its water from solely surface water sources (due to lack of additional data).

\subsection{Cooling Technology}

The primary use of water in thermoelectric power generation is related to the rejection of the waste heat. Commonly used techniques of heat rejection include once-through cooling, closed loop recirculation cooling, and dry cooling. Hybrid recirculation/dry cooling, which utilizes a combination of the dry and recirculation cooling techniques was not considered in the model presently.

1) Once-through cooling

${ }^{2}$ The SNL database is available at

http://energy.sandia.gov/climate-earth-systems/energy-water-nexus/data-modeling-analysis/water-a vailability-cost-and-use/ [2].

${ }^{3}$ The data for the remaining 12 states were not available at the time of analysis. However, these states were all in the northeastern region with plenty of water availability, which should not affect the results of the analysis here.

${ }^{4}$ From this point forward, "watershed" will refer to the HUC8 level at which the NWEM is making its decisions.

${ }^{5}$ Unappropriated water is the water remaining in a watershed that is available for appropriation (i.e., permitting and use).

${ }^{6}$ Data was retrieved from https://waterdata.usgs.gov/nwis/ on 2015-03-13 17:38:52 EDT.

${ }^{7}$ The database can be accessed at

http://www.ucsusa.org/clean-energy/energy-water-use/ucs-power-plant-database\#.WhOipNKWa70. 
In this design, the coolant (water) is pumped at a high flow rate from a proximal water resource to exchange heat with the power cycle fluid (generally at the condenser) after the final extraction of power [32]. While the once-through cooling design requires a large amount of water withdrawal, depletion (consumption) of the water resources is generally low since most of the water, apart from small evaporative losses, is discharged back to the same or different water resource generally within the same region but at higher temperatures.

Although this design represents the least expensive cooling technology option, the power plant operation becomes closely linked with the local availability and temperature of the water resource, making the plant susceptible to droughts and to higher than normal water temperatures [33] [34].

2) Recirculating (wet) cooling system

In this design, unlike the once-through system, the water after absorbing the heat rejected from the power cycle, is cooled to close to the ambient temperature through evaporative heat transfer in a cooling tower before recirculation to the power plant as a coolant [32]. While the recirculation significantly lowers the amount of water that needs to be withdrawn from the water source, the water consumption is quite a bit higher. The cost of a recirculating system is higher relative to the once-through system due to the addition of cooling towers, water treatment, and management facilities [32] [33] [35].

3) Dry cooling system

Using air via forced convection to directly cool the power cycle fluid eliminates the need for water withdrawal for cooling purposes (a small amount of make-up water will still be required in steam power plants due to regular boiler blow-downs). However, in addition to being significantly expensive (5 - 6 times) relative to even the recirculating system, [33] [35] there may be significant decrease in the performance of the system due to potentially higher heat rejection temperatures, especially during hot summers [36].

\subsection{Cooling Technology Representation in NWEM}

Each existing power station with steam as the prime mover required an assignment of the current applied cooling technology. This assignment was made based on the data found in the UCS EW3 Energy-Water Database. ${ }^{7}$ When the assignment was ambiguous, a set of rules were applied to assign the cooling technology. All new units are assumed to employ recirculating cooling initially to ensure compliance with Environmental Protection Agency Clean Water regulations.

In the case of the once-through cooling system, a significant portion of the water that is withdrawn is subsequently discharged, which can be reclaimed for other uses downstream. This is represented in the model by introducing a multiplier to the available surface water (surface, un-appropriated, and water purchased from agriculture), which allows a single gallon to be reused by several units at the same time. The multiplier attempts to model a limit for the discharge 
water reuse due to thermal limits associated with water intake, discharge, and buildup in a watershed and to account for downstream evaporation due to elevated discharge temperatures.

\subsection{Power Plant Capacity and Generation}

NEMS provides data on the existing capacity and new capacity builds of electric power generation plants along with information on the dispatch for each power plant in each of the states. Currently, the model passively uses a power generation forecast from NEMS model outputs, including both existing generating units and new builds, with no integration or active feedback. The power generation forecast from the Annual Energy Outlook 2015 Reference Case was used in this analysis.

\section{Scenarios}

NETL is interested in modeling a variety of water availability scenarios that reflect potential alternate realities with respect to hydrology and climate. Data from the World Resources Institute (WRI) Aqueduct project allows for the analysis of such scenarios without necessitating the construction or implementation of a new climate or hydrologic model. Accordingly, the model was exercised to analyze a pessimistic scenario based on WRI data as a sample to highlight the model choices. The methodology for translating the WRI data into the NWEM is described below.

\subsection{Use of Water Resources Institute Data}

The WRI data are reported based on Global Drainage Basin Database (GDBD) regions. The percentage changes in water availability through 2030 were approximated using the Total Blue Water WRI parameter, which is defined as the accumulated runoff upstream of the catchment plus the runoff in the catchment, for consistency with the reference Sandi data. Figure 3 highlights the percentage change in water available under the pessimistic scenario, which was chosen to highlight the model capabilities. This pattern of reduction of water availability was used to transform the Sandia data input to the NWEM, specifically the surface and appropriated water available. Groundwater, Brackish Groundwater, and Municipal Wastewater availability are assumed to remain constant at their 2012 Sandia data levels throughout the forecast period. Factors affecting surface and shallow groundwater, such as precipitation, drought, etc. are not assumed to affect deep, brackish groundwater or municipal wastewater availability.

\subsection{Application of WRI Data to NWEM}

Estimates for the intermediate years (between 2015-2030) are linearly interpolated within the model and the resulting percentages are used to adjust the 2015 estimated appropriated and surface water supplies for each watershed region for each year through 2030. Figure 4 below displays the resulting surface water 


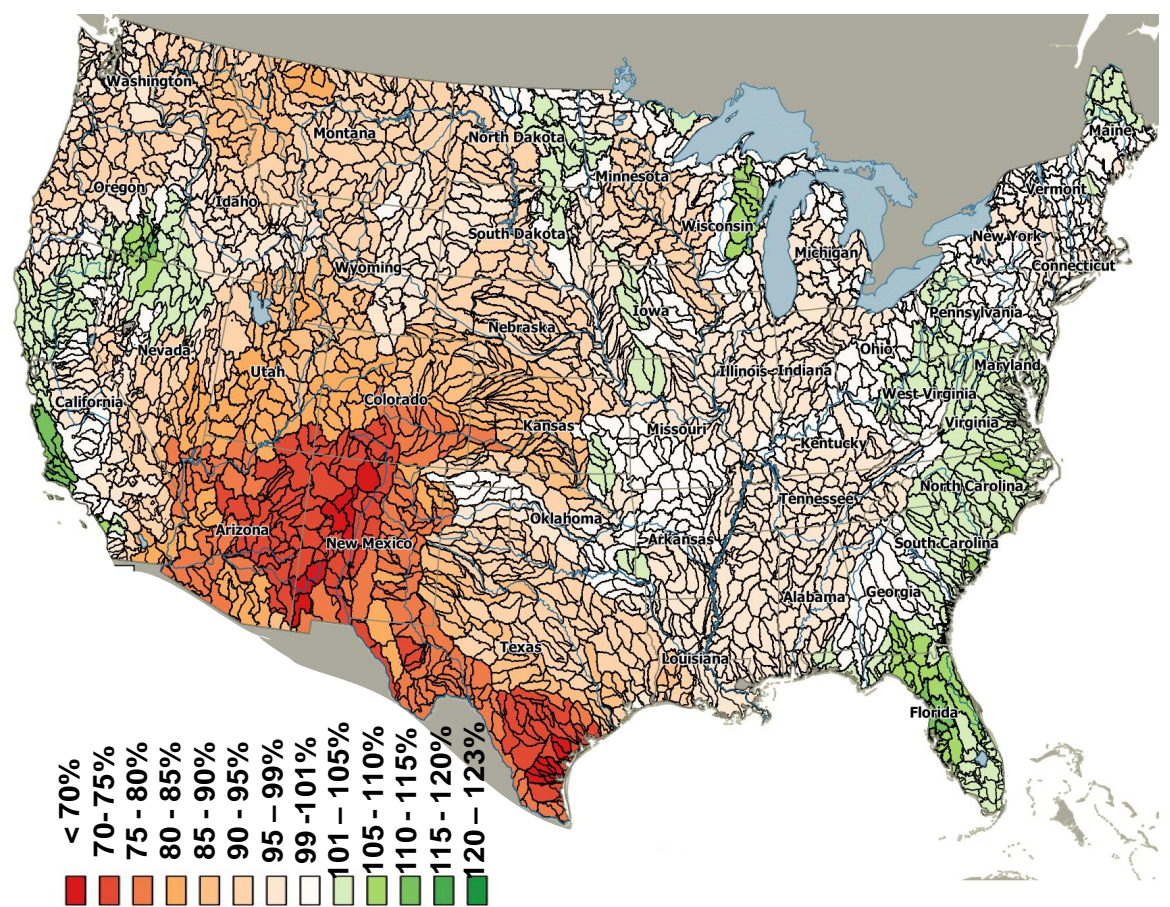

Figure 3. Percentage change in total blue water between 2010 and 2030, pessimistic case.

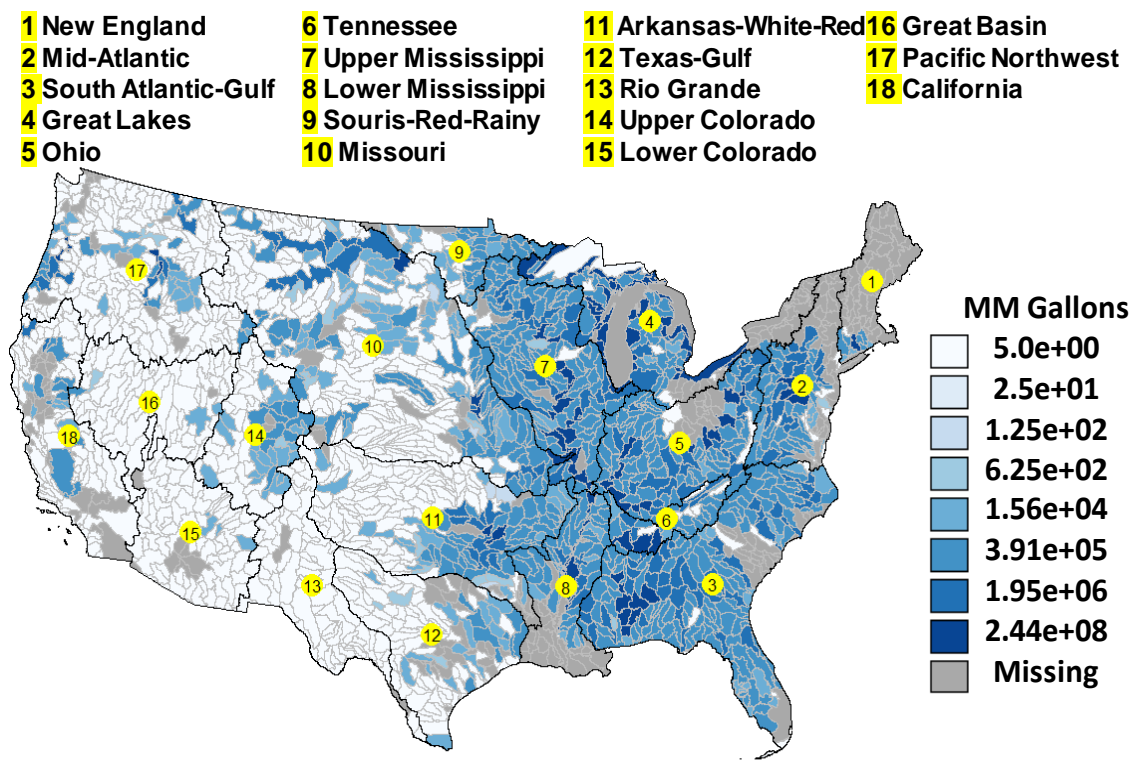

Figure 4. Surface water availability in 2030, pessimistic case.

availability in year 2030. The HUC2 level (basin level) regions are also outlined for discussion later.

\section{Results}

The NWEM results presented here serve as an illustration of the trade-offs considered by the model when subjected to the static generation forecast imposed by NEMS. More realistic scenarios could be projected with the additional choices of 
power generation curtailment or usage of alternate technologies enabled by the dynamic linking with NEMS in the next phase of model development.

\subsection{National}

While the NWEM operates at a watershed level, the model decisions were aggregated over all watershed regions to discern the impacts at a national level (38 states). The total retrofits chosen by the model by cooling technology type are shown in Figure 5, which indicates that a total of $1.8 \mathrm{GW}$ of dry cooling (from recirculating) and $10.3 \mathrm{GW}$ of recirculating cooling (from once-through cooling) were selected by the model over the forecast period. The model projects several retrofits in the first year, driven by an initial imbalance in the water supply and the projected water needs of the power sector.

The distribution of the model's selection of retrofits by basin level (HUC2) regions is shown in Figure 6, which reveals that most of the retrofits were in the

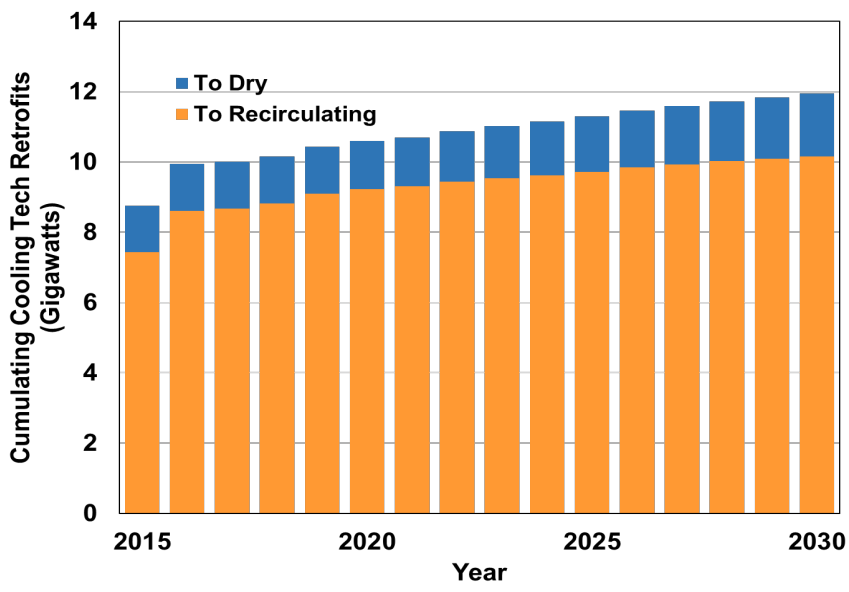

Figure 5. Projected cooling technology retrofits.

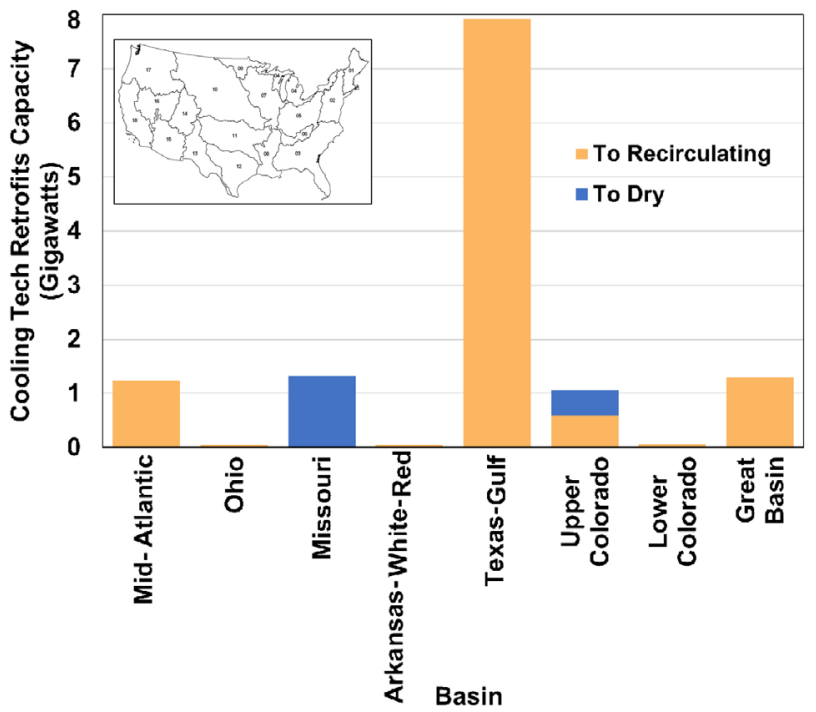

Figure 6. Projected cooling technology retrofits capacity by basin level. 
western U.S. with the Texas-Gulf basin (basin 12) accounting for over half of the retrofits.

Figure 7 shows the predicted purchases of water across time across the country wherever deemed as the economically optimal alternative by the NWEM. The model evaluates relative savings of purchasing water from the alternative sources in the watershed vis-à-vis reducing its water needs (either draw or consumption) by investing in a retrofit. The total water purchases are indicated to rise from about 50 billion gallons per year in 2015 to about 59 billion gallons in 2030.

The corresponding regional (basin level) distribution, shown in Figure 8, for the year 2030 reveals that most of the purchases were in the Rio Grande, Upper Colorado, and Lower Colorado basins, the dryer parts of the West and Southwest, which appropriately did not commit to significant retrofits during the time horizon of the model.

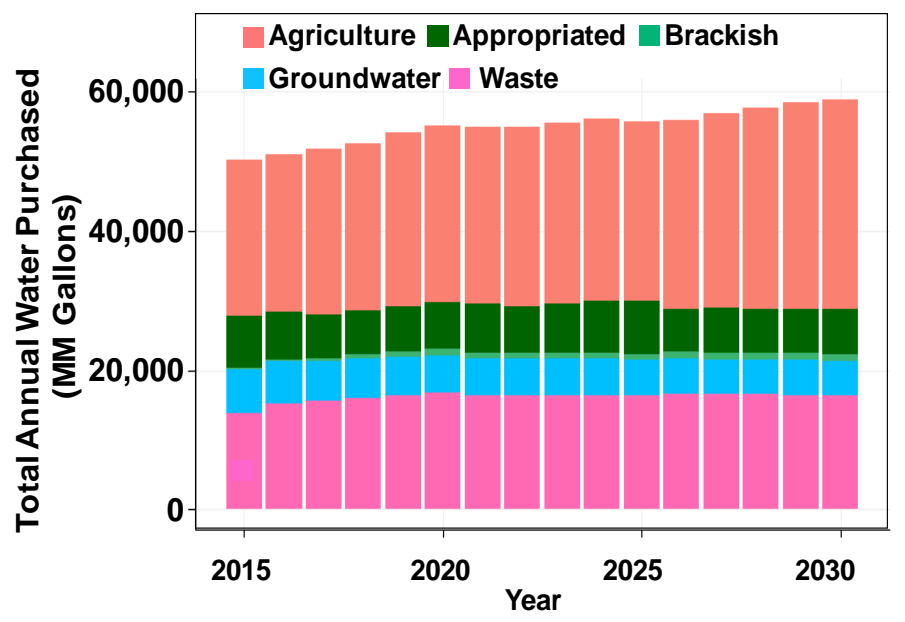

Figure 7. Total annual water purchased by basin level.

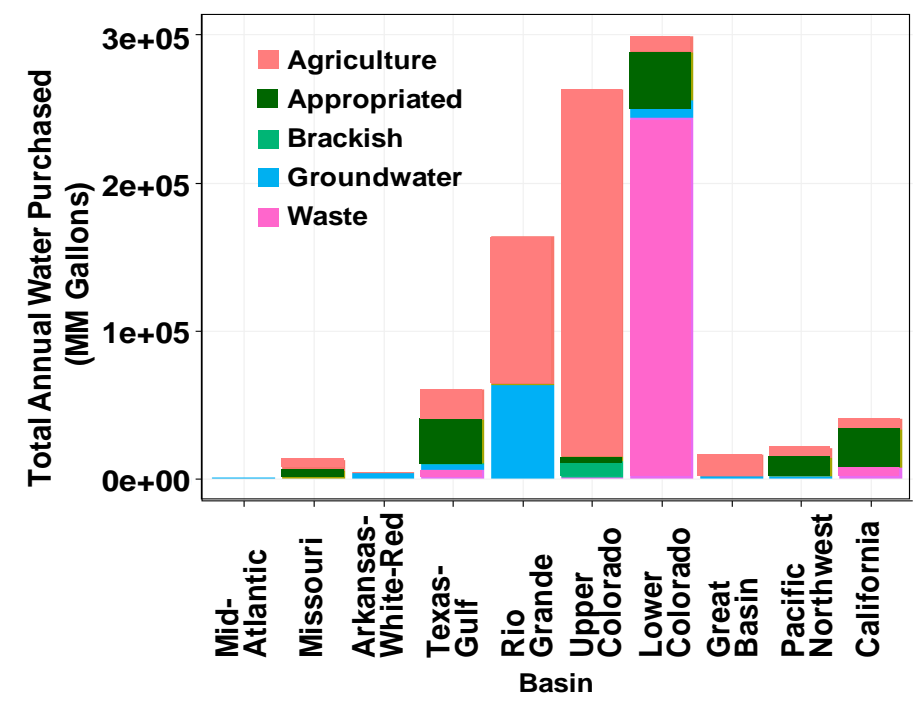

Figure 8. Total annual water purchased for use nationally. 


\subsection{Detailed Results}

Due to the localized nature of the water supply, the most interesting modeling insights are revealed at the watershed level. The following results focus on the Texas-Gulf basin where the largest numbers of retrofits were predicted.

\subsubsection{Retrofits and Water Purchases}

Several watersheds face reduced supplies of water under the pessimistic scenario in the Texas-Gulf basin. Figure 9 displays the distribution of the power plant cooling retrofits chosen by the model in the Texas-Gulf area by watershed as an economic solution to the projected scarcity of freely available surface water. The alternative of curtailing power plant dispatch will also be considered in the next phase of the NWEM development when it actively interfaces with the NEMS routines. As shown below in Figure 10, even after retrofitting, the power stations operating in each watershed continued to use multiple sources of water, including purchases.

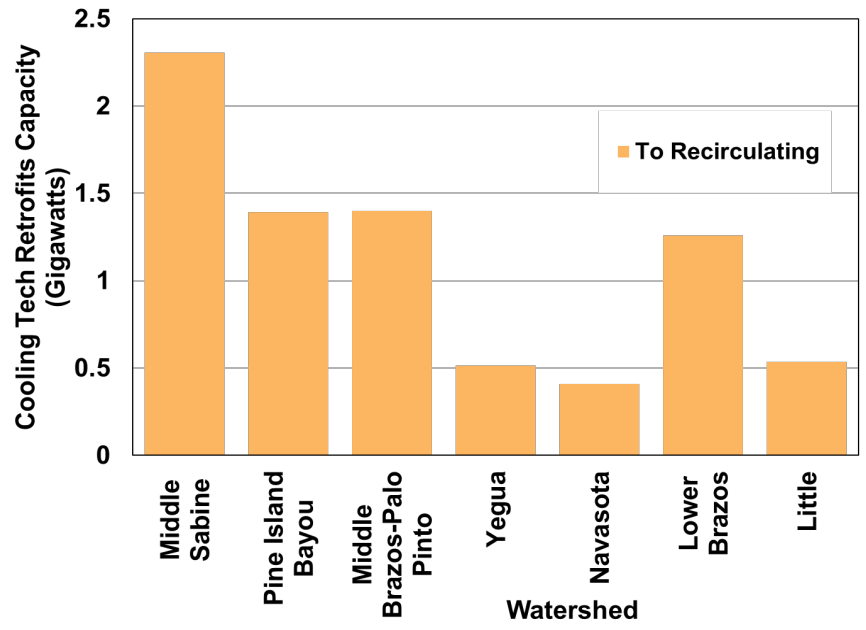

Figure 9. Retrofits in the Texas-Gulf basin.

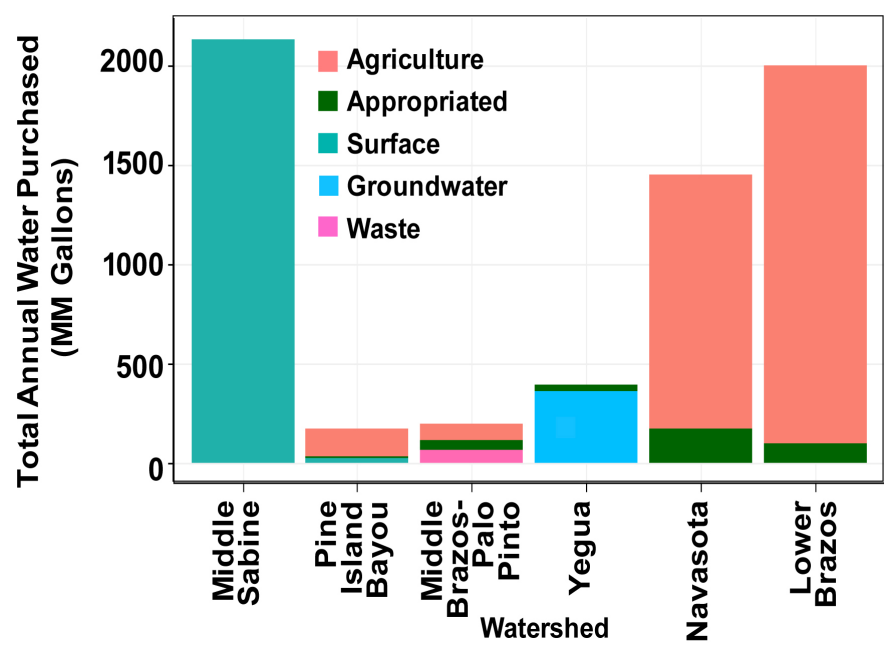

Figure 10. Water purchases by watershed in the Texas-Gulf basin. 
Figure 11 displays the change in cooling technology over the model horizon for the Navasota watershed within the Texas-Gulf basin. While two of the three units within this watershed already use recirculating cooling, the third unit gradually converts most of its once-through cooling capacity to recirculating cooling as it comes under increasing pressure from shrinking water supplies. The NWEM currently assumes that gradual retrofitting is possible although the model can implement other assumptions such as discrete retrofit steps at the unit-level.

The supply of water by source in the same watershed is shown in Figure 12 below. Albeit the surface water availability within this watershed reduces to a value of zero as we approach 2030 under the WRI pessimistic scenario, the overall availability reduces at a lower rate partially due to the water freed up (or not used) by the retrofitting power station (station 4576 in this case). As shown in the figure, the water that could be freed by additional retrofitting to recirculating

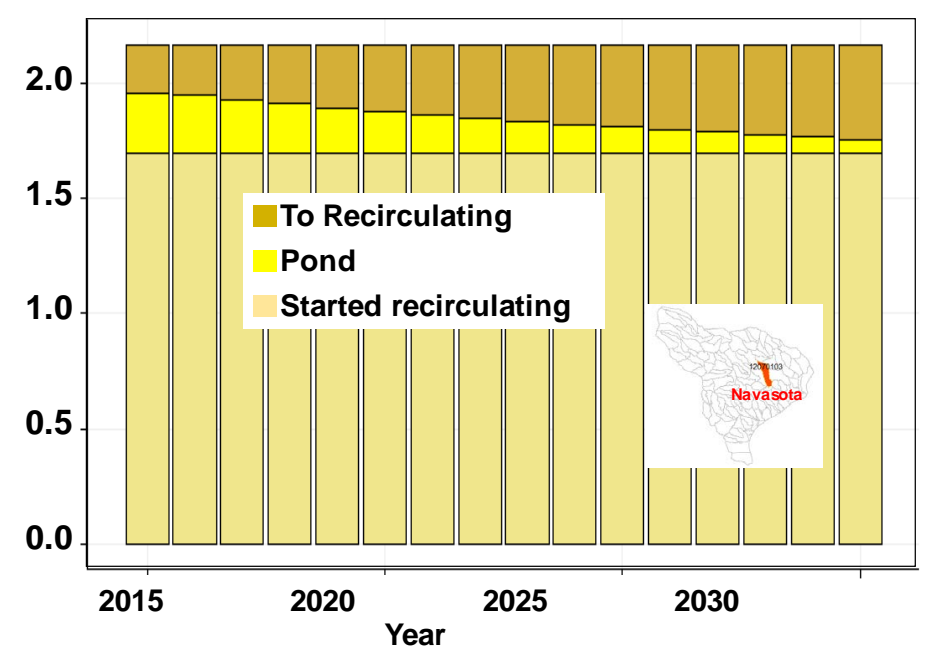

Figure 11. Changes in cooling tech-Navasota watershed.

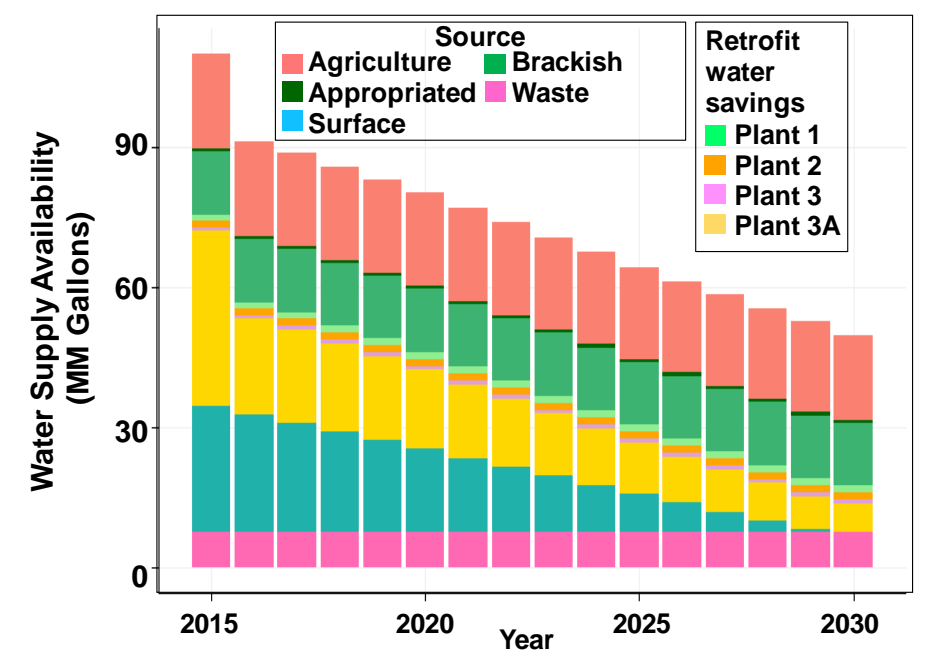

Figure 12. Water supply by source-Navasota watershed. 
cooling by power station 4576 is shrinking-reflecting that in the prior year a partial retrofit was undertaken.

In response to the shrinking supplies, each end use sector (power stations and agriculture, in this case), adjust their water consumption. Figure 13 highlights the reduction in water withdrawal by the one power station that is continually expanding its shift to recirculating cooling (as shown in Figure 12).

In addition to reducing water withdrawal as shown above, Figure 14 highlights that by 2025 there is insufficient water available to meet the consumption needs of the power stations without purchasing water from the agriculture sector. Note that for the power station that is increasingly relying on recirculating cooling to reduce its water draw, the consumption of water did not change (i.e., the gallons per MWh of water consumed by pond and recirculating are set the same in this data set).

Figure 15 shows both water withdrawal and consumption side by side (note the substantial differences in the scale of the two figures). The figure on the right highlights that with the retrofitting to recirculating cooling (RC), the freeing of water into the surface category is still positive. However, the figure on the right indicates that to meet their consumption needs, the power stations need to

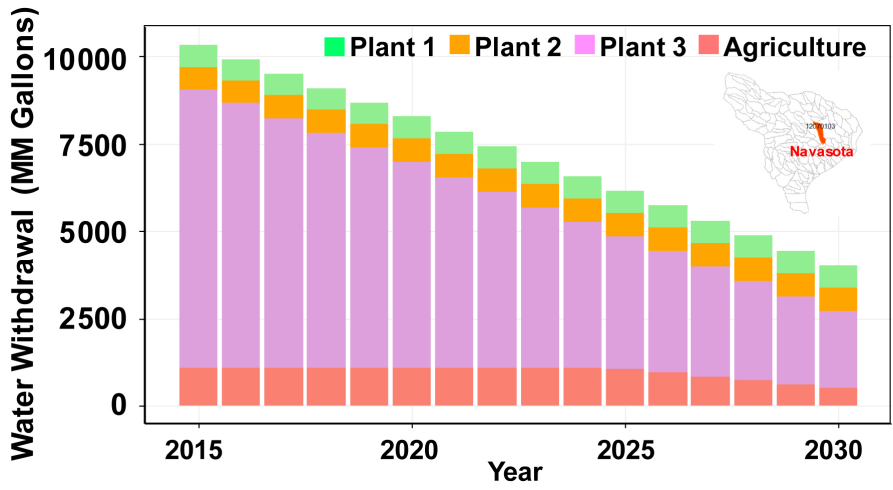

Figure 13. Water withdrawal by sector-Navasota watershed in Summer.

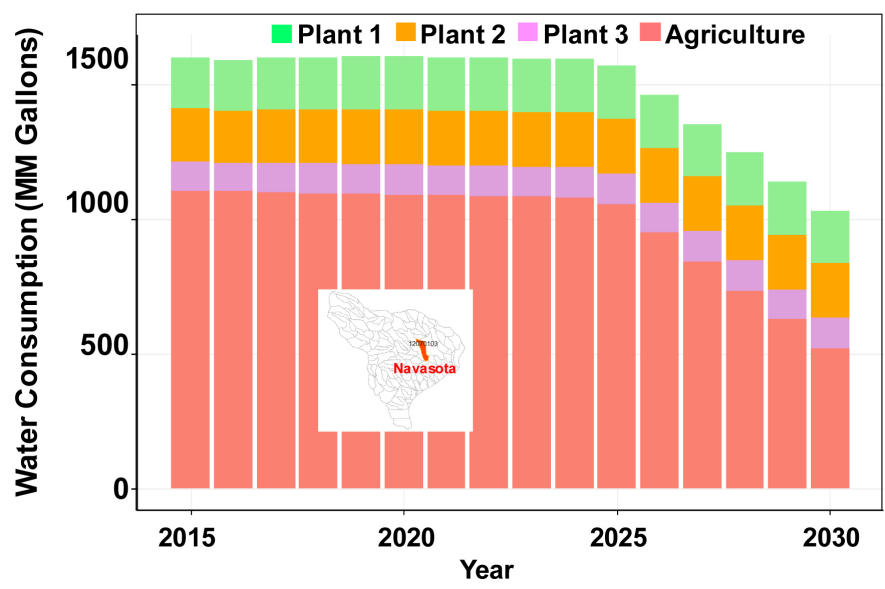

Figure 14. Water consumption-Navasota watershed. 

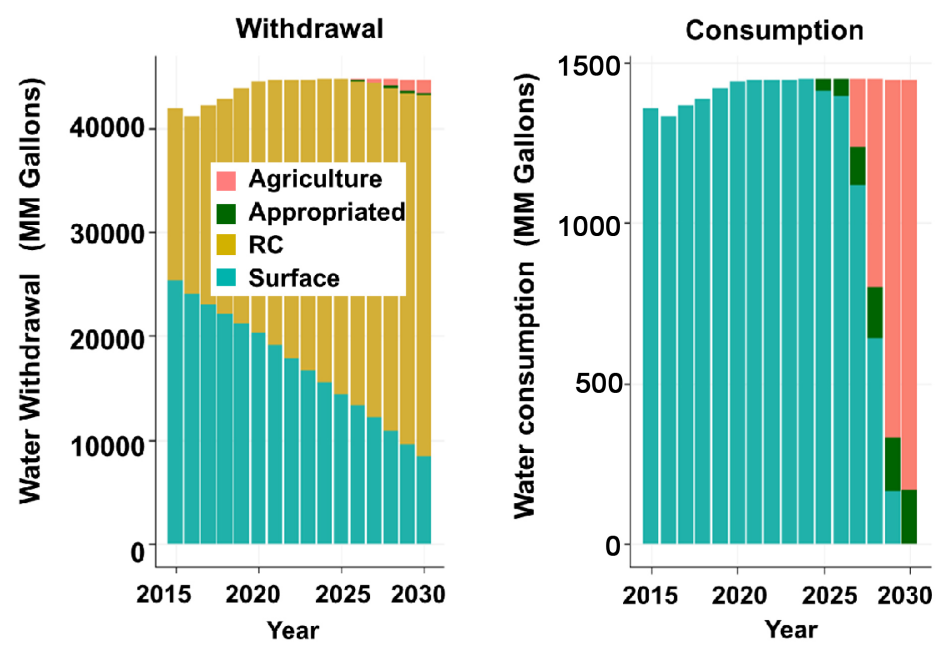

Figure 15. Water withdrawal and consumption-Navasota watershed.

purchase water to satisfy their needs. The model assumes that the agriculture water purchased to meet the draw needs of a power station is no longer available to agriculture.

\subsubsection{Water Markets}

A unique part of the NWEM design is its formulation around potential markets for water. This framework allows for the allocation of water based on its marginal value. In any given watershed there are frequently multiple sources of water such as brackish water (requiring treating at some cost), groundwater (again, potentially requiring treatment), appropriated water that can be purchased from its owner, unappropriated water, and water being used by agriculture. The calculations spanned across seasons to capture the significant water supply variation across seasons.

The NWEM selection of the combination of water sources that minimize the cost of water supply and use by the power stations over the planning horizon (10 years) can be utilized to construct a market supply curve for water. The black lines in Figure 16 and Figure 17 represent the water supply cost curve in the selected watershed.

In each of these figures, the charts on the left show the supply curves with appropriate scales to capture the associated quantities. The figures on the right show an expanded scale on both the axes to permit a closer inspection of the market clearing points and the associated implied market price.

As shown in Figure 16, in the year 2020, the market clearing price was $\$ 0.21$ per thousand gallons. The quantity purchased in this season and watershed was 8.27 million gallons. In this season, and year, the marginal cost of the water was tied to the retrofit to recirculating cooling.

In the year 2030, shown in Figure 17, the market clearing price has increased to $\$ 0.81$ per thousand gallons while the quantity purchased decreased to 4.0 million gallons. The water supply limit was 23 million gallons in 2020 and decreased 
Expanded Scale

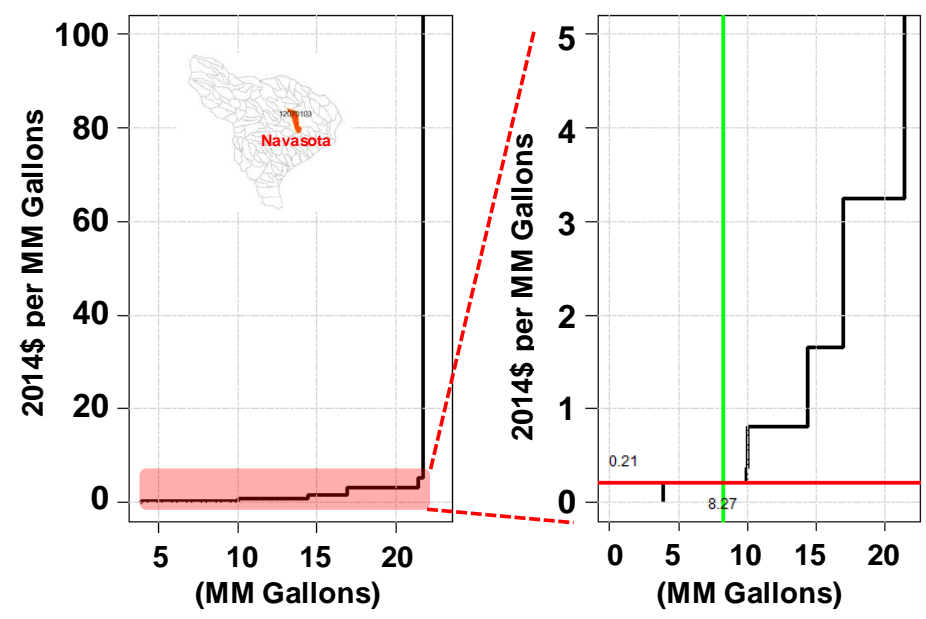

Figure 16. Supply curves-Navasota watershed Summer 2020.

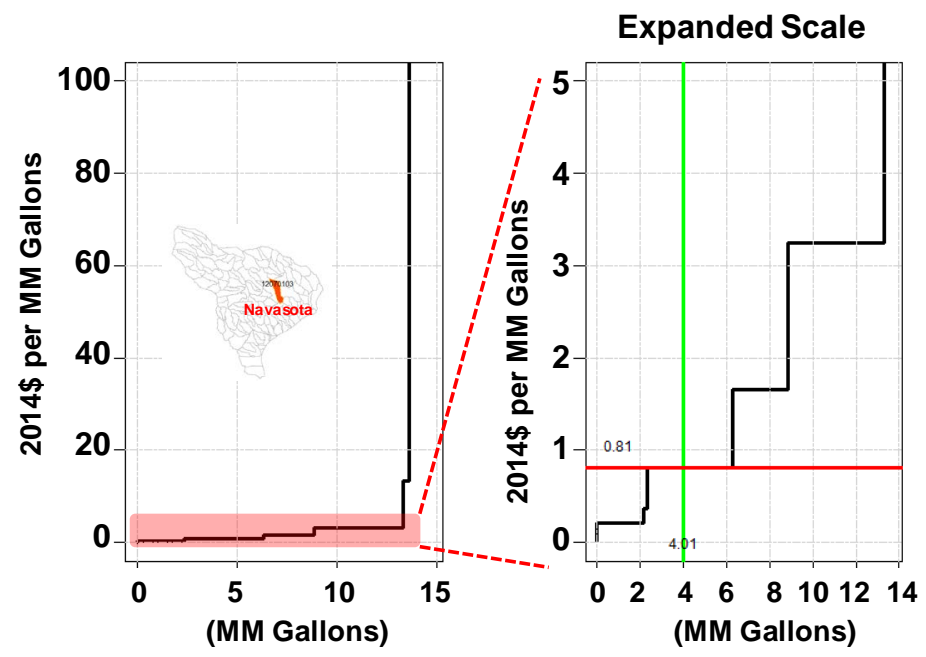

Figure 17. Supply curves-Navasota watershed Summer 2030.

to 14.7 million gallons in 2030 , which forces the power stations to purchase water from agriculture, driving up the market price.

\section{Discussion}

Water use has become a significant issue in parts of the country including California and Texas, both of which experience significant droughts on a recurring basis. Under various scenarios, drought- and water-related issues could grow and become a more pervasive problem. Water is a key resource used by industry, municipal agencies and households, agriculture, power generation, and others. As discussed in this paper, NETL's development of the NWEM represents a first step in developing a comprehensive framework that approaches water in the context of supply and demand within a market framework. NWEM is comprehensive both geographically and in its ability to flexibly address current and future water requirements across sectors. 
By addressing water in this manner, the NWEM offers insights into the relative value of water in differing applications and enhances the opportunity for better coordination among planners and policy makers. This paper discusses a prototype model that demonstrates the efficacy of the approach and reveals trade-offs from the power and agriculture sector's points of view. Since the prototype only passively utilized a forecast of power generation from an existing forecast, the model's choices were limited to water purchases or retrofitting to meet future water supply constraints. The need for modeling at the watershed level to resolve the highly local nature of the water resources is also demonstrated by the results.

In the next phase, NETL will integrate the water sub-module into the NEMS framework, which will allow active interaction between the water market and power markets extending the industry's ability to re-dispatch its generating units with the price of water as one of the variable costs. This option may be preferred economically in many instances to investing in retrofits or purchasing water from alternative sources. Additional efforts that are being planned include extending the water modeling to other energy sectors (e.g., oil and gas extraction) and enhancements to the industry and municipal water usage models with potential linkages to population and economic models. Additional water rights constraints can also be prescribed. The coupling with NEMS would also permit a life cycle analysis of regional water supply and consumption.

The NWEM model currently uses the Sandia data as a reference database for the analysis described. However, the model has been designed with the flexibility to accept water supply data with higher fidelity. The WRI data was employed in this first phase to demonstrate the efficacy of modeling different scenarios with respect to future water availability. Ultimately, the NWEM can be coupled to a more extensive water resource model such as the WEAP [22] or WRS models [30], which can consider climate change effects in a dynamic fashion.

\section{Conclusion}

A simplified energy-water prototype model (NWEM) has been developed at NETL as a part of a larger effort to comprehensively model energy-water interactions. The NWEM passively couples a variety of data on water supply, water availability, and power plant water use with NEMS power generation forecasts. NWEM operates at a watershed level and its efficacy in resolving local water supply and water-use trade-offs were demonstrated using the Sandia data along with a water supply scenario projected by WRI. Since the prototype only passively utilized a forecast of power generation from an existing forecast, the model's choices were limited to purchases or retrofitting to meet future water supply constraints. In the next phase, NETL will integrate the water sub-module into the NEMS framework, which will allow active interaction between the water market and power markets, extending the industry's ability to re-dispatch its generating units with the price of water as one of the variable costs. 


\section{Acknowledgements}

This work was funded by NETL under the DE-FE0025912 contract for site support services, which is gratefully acknowledged.

\section{Disclaimer}

This report was prepared as an account of work sponsored by an agency of the United States Government. Neither the United States Government nor any agency thereof, nor any of their employees, makes any warranty, express or implied, or assumes any legal liability or responsibility for the accuracy, completeness, or usefulness of any information, apparatus, product, or process disclosed, or represents that its use would not infringe privately owned rights. Reference therein to any specific commercial product, process, or service by trade name, trademark, manufacturer, or otherwise does not necessarily constitute or imply its endorsement, recommendation, or favoring by the United States Government or any agency thereof. The views and opinions of authors expressed therein do not necessarily state or reflect those of the United States Government or any agency thereof.

\section{References}

[1] Goldstein, R. and Smith, W. (2002) Water and Sustainability: U.S. Electricity Consumption for Water Supply and Treatment. EPRI.

[2] Pate, R., Hightower, M., Cameron, C. and Einfeld, W. (2007) Overview of Energy-Water Interdependencies and the Emerging Demands on Water Resources. Sandia National Laboratories, Albuquerque.

[3] Feeley, T.J., Skone, T.J., Stiegel, G., McNemar, A., Nemeth, M., Schimmoller, B., Murphy, J. and Manfredo, L. (2008) Water: A Critical Resource in the Thermoelectric Power Industry. Energy, 33, 1-11. https://doi.org/10.1016/j.energy.2007.08.007

[4] NETL National Energy Technology Laboratory (2010) Water Vulnerabilities for Existing Coal-Fired Power Plants. NETL.

[5] Elcock, D. (2010) Future U.S. Water Consumption: The Role of Energy Production. Journal of the American Water Resources Association, 46, 447-460. https://doi.org/10.1111/j.1752-1688.2009.00413.x

[6] Sovacool, B.K. and Sovacool, K.E. (2009) Identifying Future Electricity-Water Tradeoffs in the United States. Energy Policy, 37, 2763-2773. https://doi.org/10.1016/j.enpol.2009.03.012

[7] Dodder, R.S. (2014) A Review of Water Use in the U.S. Electric Power Sector: Insights from System Level Perspectives. U.S. Environmental Energy Science Papers.

[8] Davies, E.G.R., Kyle, P. and Edmonds, J.A. (2013) An Integrated Assessment of Global and Regional Water Demands for Electricity Generation to 2095. Advances in Water Resources, 52, 296-313. https://doi.org/10.1016/j.advwatres.2012.11.020

[9] Kyle, P., Davies, E.G.R., Dooley, J.J., Smitha, S.J., Clarke, L.E., Edmonds, J.A. and Hejazi, M. (2013) Influence of Climate Change Mitigation Technology on Global Demands of Water for Electricity Generation. International Journal of Greenhouse Gas Control, 13, 112-123. https://doi.org/10.1016/j.ijggc.2012.12.006

[10] Dooley, J.J., Kyle, P. and Davies, E.G.R. (2013) Climate Mitigation's Impact on Global and Regional Electric Power Sector Water Use in the 21st Century. Energy 
Procedia, 37, 2470-2478. https://doi.org/10.1016/j.egypro.2013.06.128

[11] Hejazi, M., Edmonds, J., Clarke, L., Kyle, P., Davies E., Chaturvedi, V., Wise, M., Patel, P., Eom, J., Calvin, K., Moss, R. and Kim, S. (2014) Long-Term Global Water Projections using Six Socioeconomic Scenarios in an Integrated Assessment Modeling Framework. Technological Forecasting \& Social Change, 81, 205-226. https://doi.org/10.1016/j.techfore.2013.05.006

[12] Liu, L., Hejazi, M., Patel, P., Kyle, P., Davies, E., Zhou, Y., Clarke, L. and Edmonds, J. (2015) Water Demands for Electricity Generation in the U.S.: Modeling Different Scenarios for the Water-Energy Nexus. Technological Forecasting \& Social Change, 94, 318-334. https://doi.org/10.1016/j.techfore.2014.11.004

[13] Chandel, M.K., Pratson, L.F. and Jackson, R.B. (2011) The Potential Impacts of Climate-Change Policy on Freshwater Use in Thermoelectric Power Generation. Energy Policy, 39, 6234-6242. https://doi.org/10.1016/j.enpol.2011.07.022

[14] Ackerman, F. and Fisher, J. (2013) Is There a Water-Energy Nexus in Electricity Generation? Long-Term Scenarios for the Western United States. Energy Policy, 59, 235-241. https://doi.org/10.1016/j.enpol.2013.03.027

[15] Roy, S.B., Chen, L., Girvetz, E.H., Maurer, E.P., Mills, W.B. and Grieb, T.M. (2012) Projecting Water Withdrawal and Supply for Future Decades in the U.S. under Climate Change Scenarios. Environmental Science \& Technology, 46, 2545-2556. https://doi.org/10.1021/es2030774

[16] Akhtar, M.K.A., Wibe, J., Simonovic, S.P. and MacGee, J. (2013) Integrated Assessment Model of Society-Biosphere-Climate-Economy-Energy System. Environmental Modelling \& Software, 49, 1-21. https://doi.org/10.1016/j.envsoft.2013.07.006

[17] Lubega, W.N. and Farid, A.M. (2013) An Engineering Systems Model for the Quantitative Analysis of the Energy-Water Nexus. Complex Systems Design \& Management, 219-231.

[18] Lubega, W.N. and Farid, A.M. (2014) Quantitative Engineering Systems Modeling and Analysis of the Energy-Water Nexus. Applied Energy, 135, 142-157. https://doi.org/10.1016/j.apenergy.2014.07.101

[19] Tidwell, V. and Moreland, B. (2011) Energy and Water in the Great Lakes. Sandia National Laboratories. https://doi.org/10.2172/1031312

[20] Nanduri, V. and Otieno, W. (2011) A New Water and Carbon Conscious Electricity Market Model for the Electricity-Water-Climate Change Nexus. The Electricity Journal, 24, 64-74. https://doi.org/10.1016/j.tej.2011.09.021

[21] Nanduri, V. and Saavedra-Antolínez, I. (2013) A Competitive Markov Decision Process Model for the Energy-Water-Climate Change Nexus. Applied Energy, 111, 186-198. https://doi.org/10.1016/j.apenergy.2013.04.033

[22] Yates, D., Averyt, K., Flores-Lopez, F., Meldrum, J., Sattler, S., Sieber, J. and Young, C. (2013) A Water Resources Model to Explore the Implications of Energy Alternatives in the Southwestern US. Environmental Research Letters, 8, 4.

https://doi.org/10.1088/1748-9326/8/4/045004

[23] Yates, D., Meldrum, J., Flores-Lopez, F. and Davis, M. (2013) Integrated Impacts of Future Electricity Mix Scenarios on Select Southeastern US Water Resources. Environmental Research Letters, 8, 3. https://doi.org/10.1088/1748-9326/8/3/035042

[24] Yates, D., Meldrum, J. and Averyt, K. (2013) The Influence of Future Electricity Mix Alternatives on Southwestern US Water Resources. Environmental Research Letters, 8, 4. https://doi.org/10.1088/1748-9326/8/4/045005

[25] Stillwell, A.S. (2013) Water Impacts on Thermoelectric Power Generation. Dissertation, The University of Texas at Austin, Austin. 
[26] Sattler, S., Macknick, J., Yates, D., Flores-Lopez, F., Lopez, A. and Rogers, J. (2012) Linking Electricity and Water Models to Assess Electricity Choices at Relevant Scales. Environmental Research Letters, 7, 4. https://doi.org/10.1088/1748-9326/7/4/045804

[27] Cohen, S.C., Macknick, J., Averyt, K. and Meldrum, J. (2014) Modeling Climate-Water Impacts on Electricity Sector Capacity Expansion. ASME Power 2014 Conference.

[28] Macknick, J., Sattler, S., Averyt, K., Clemmer, S. and Rogers, J. (2012) The Water Implications of Generating Electricity: Water Use across the United States Based on Different Electricity Pathways through 2050. Environmental Research Letters, 7, 4. https://doi.org/10.1088/1748-9326/7/4/045803

[29] Macknick, J., Cohen, S., Newmark, R., Martinez, A., Sullivan, P. and Tidwell, V.C. (2015) Water Constraints in an Electric Sector Capacity Expansion Model. NREL. https://doi.org/10.2172/1215271

[30] Blanc, E., Strzepek, K., Schlosser, A., Jacoby, H., Gueneau, A., Fant, C., Rausch, S. and Reilly, J. (2014) Modeling U.S. Water Resources under Climate Change. Earth's Future, 2, 197-244. https://doi.org/10.1002/2013EF000214

[31] NETL National Energy Technology Laboratory. NETL Water Energy Prototype Model Methodology. NETL.

[32] Averyt, K., Fisher, J., Huber-Lee, A., Lewis, A., Macknick, J., Madden, N., Rogers, J. and Tellinghuisen, S. (2011) Freshwater Use by U.S. Power Plants: Electricity's Thirst for a Precious Resource. A Report of the Energy and Water in a Warming World Initiative. Union of Concerned Scientists, Cambridge.

[33] Water in the West (2013) Water and Energy Nexus: A Literature Review. Water in the West, Stanford University, Stanford.

[34] Forster, H. and Lilliestam, J. (2010) Modeling Thermoelectric Power Generation in view of Climate Change. Regional Environmental Change, 10, 327-338. https://doi.org/10.1007/s10113-009-0104-x

[35] Loew, A., Jaramillo, P. and Zhai, H. (2016) Marginal Costs of Water Savings from Cooling System Retrofits: A Case Study for Texas Power Plants. Environmental Research Letters, 11, 10. https://doi.org/10.1088/1748-9326/11/10/104004

[36] Zhai, H., Rubin, E.S. and Versteeg, P.L. (2011) Water Use at Pulverized Coal Power Plants with Post-Combustion Carbon Capture and Storage. Environmental Science \& Technology, 45, 2479-2485. https://doi.org/10.1021/es1034443 